Napoléon BONAPARTE, Correspondance générale, publiée par la Fondation Napoléon, Tome cinquième : Boulogne, Trafalgar, Austerlitz, 1805

Paris, Fayard, 2008, 1128 p., ISBN 978-2-213-63721-1, $52 €$

Matthieu de Oliveira

\title{
OpenEdition
}

Journals

Édition électronique

URL : https://journals.openedition.org/ahrf/11587

DOI : $10.4000 /$ ahrf. 11587

ISSN : 1952-403X

Éditeur :

Armand Colin, Société des études robespierristes

Édition imprimée

Date de publication : 1 octobre 2009

Pagination : 203-204

ISBN : 978-2-200-92560-4

ISSN : 0003-4436

Référence électronique

Matthieu de Oliveira, « Napoléon bonaparte, Correspondance générale, publiée par la Fondation Napoléon, Tome cinquième : Boulogne, Trafalgar, Austerlitz, 1805 », Annales historiques de la Révolution française [En ligne], 358 | octobre-décembre 2009, mis en ligne le 29 juillet 2010, consulté le 24 avril 2022. URL : http://journals.openedition.org/ahrf/11587 ; DOI : https://doi.org/10.4000/ahrf.11587

Ce document a été généré automatiquement le 24 avril 2022.

Tous droits réservés 


\section{Napoléon BONAPARTE, Correspondance générale, publiée par la Fondation Napoléon, Tome cinquième : Boulogne, Trafalgar, Austerlitz, 1805}

Paris, Fayard, 2008, 1128 p., ISBN 978-2-213-63721-1, $52 €$

\section{Matthieu de Oliveira}

\section{RÉFÉRENCE}

Napoléon BONAPARTE, Correspondance générale, publiée par la Fondation Napoléon, Tome cinquième : Boulogne, Trafalgar, Austerlitz, 1805, Paris, Fayard, 2008, 1128 p., ISBN 978-2-213-63721-1, $52 €$

1 La publication, initiée en 2002 par la Fondation Napoléon, d'une nouvelle édition de la correspondance de Napoléon Bonaparte, en intégrant une masse considérable de lettres inédites, se poursuit avec ce cinquième tome. Les tomes II (La campagne d'Égypte et l'avènement, 1798-1799) et III (Pacifications, 1800-1802) ayant déjà fait l'objet de recensions dans les colonnes des AHRF (respectivement aux numéros 346 d'octobre-décembre 2006 et 248 d'avril-juin 2007), on se dispensera de présenter les invariants de chaque volume.

2 L'année 1805 est sans doute l'une des plus riches de la vie de Napoléon Bonaparte : au lendemain du Sacre et jusqu'aux lendemains d'Austerlitz, il imprime sa marque à la France comme à l'Europe, supervisant la nouvelle numérotation des rues de Paris (début février) comme l'organisation de la République batave (de la fin mars à la fin avril), devant faire face à la troisième coalition alors même qu'il est couronné roi d'Italie (fin mai) et qu'il opère le rattachement de l'ex-République ligurienne à l'Empire (juin), puis engageant fin août la manœuvre stratégique qui le mène des rives de la Mer du Nord au cœur de l'Europe à l'automne et lui assure une victoire éclatante sur le plateau de Pratzen; cette dernière permet de rétablir une confiance mise à mal par la 
grave crise financière qui secoue le pays à la suite de la faillite des Négociants réunis et la défaite navale de Trafalgar (21 octobre).

De tous ces événements, la correspondance de l'empereur est naturellement le reflet. Ce cinquième tome rassemble les 1764 lettres (inédites à $35 \%$ ) écrites ou dictées au cours de l'année - soit une moyenne de près de cinq lettres par jour -, de 55 lieux de rédaction et à 156 destinataires différents. Les premiers d'entre eux sont sans surprise ses principaux collaborateurs et ministres (Cambacérès, Champagny, Decrès, Fouché, Gaudin, Lebrun, Talleyrand) et ses maréchaux et généraux (Eugène de Beauharnais, Berthier, Lannes, Murat), mais ces missives concernent directement ou indirectement près de 1300 personnages heureusement recensés dans un volumineux index nominum (p. 1053-1123), chacun d'entre eux faisant l'objet d'une présentation succincte mais fort utile. Une répartition thématique des missives permet de distinguer trois grands ensembles, respectivement consacrés aux questions militaires (44\%), diplomatiques (22\%) et intérieures ou générales (le reste). On observe à la lecture que certaines journées sont particulièrement chargées sur le plan épistolaire, à l'image de celle du 13 décembre 1805 : à peine dix jours après Austerlitz, l'empereur dicte de Schönbrunn un total de seize lettres; la plupart concernent des sujets militaires et évoquent les pourparlers de paix en cours, mais on le voit discutant de la route du Simplon avec le directeur général des Ponts et chaussées, rétablir l'ordre à l'Institut en exigeant le silence du mathématicien Lalande, qui professe l'athéisme, et on le surprend, tendre et attentionné, remerciant sa belle-fille Hortense d'une lettre que lui a fait parvenir le fils aîné de cette dernière, le jeune Napoléon alors âgé de trois ans (lettre 11 174).

Le volume propose enfin, comme les précédents, une série d'études particulières : à « La politique italienne de Napoléon" (A. Pillepich) répond un examen de "La stratégie maritime de Napoléon en 1805 » (amiral R. Monaque); la présentation du «Camp de Boulogne » par F. Beaucour est en fait une réédition du texte publié dans le Dictionnaire Napoléon (sans la bibliographie cependant) et trouve un prolongement logique dans celle de "La Grande Armée de 1805 » (G. Madec) qui s'emploie à présenter l' "ordre de bataille " des quelques 200000 hommes (principalement Français, mais aussi Italiens, Bataves et Rhénans) qui la composent, répartis en huit corps d'armée soutenus par une imposante cavalerie, forte de 15600 hommes. Les deux autres études, consacrées aux lettres devenues documents et à ceux qui les ont rédigées et classées, présentent un intérêt particulier en ce qu'elles donnent à voir l'empereur et ses secrétaires au travail et rappellent les conditions de constitution d'un fonds d'archives au sommet de l'État (les pages de J.-B. Auzel sont à cet égard éclairantes). Les deux « scribes » successifs de l'empereur font enfin l'objet d'une notice plus ou moins développée : Meneval, en poste de 1802 à 1812, présenté par M. Allégret, obligé de mettre au point une sténographie particulière lui permettant de faire face à la rapidité de la dictée impériale et qui dispose, après deux heures de tête à tête avec Napoléon, de quoi remplir sa journée de travail jusqu'à la séance de signature vespérale, et le baron Fain, son subordonné puis son successeur jusqu'en 1815. Autour d'eux, un personnel somme toute restreint et totalement dévoué à l'empereur; à ses côtés, on note la présence d'un interprète particulier, l'auditeur au Conseil d'État Lelorgne d'Ideville, sans qu'on sache rien des langues qu'il connaissait (le russe et l'allemand, selon le Dictionnaire biographique des membres du Conseil d'État, 1799-2002, Paris, Fayard, 2004, p. 88). On pourra regretter l'absence d'une étude spécifique sur les causes, les effets et les suites du krach des 
Négociants réunis, peut-être reporté au volume suivant, comme le sous-entend l'introduction (p. 13).

5 Parmi les annexes, on retrouve les tables équivalences des unités de mesure et autres monnaies, même si l'on peut s'étonner de la mention des assignats et des mandats territoriaux, depuis longtemps disparus de la circulation en 1805. 